\title{
Enantioselective Fluorescent Recognition of Amino Alcohols by a Chiral Tetrahydroxyl 1,1'-Binaphthyl Compound
}

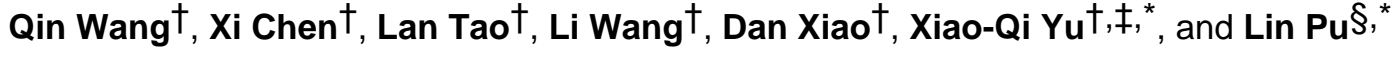 \\ $\dagger$ Department of Chemistry, Key Laboratory of Green Chemistry and Technology (Ministry of Education), \\ Sichuan University, Chengdu, Sichuan 610064, P. R. China \\ $\$$ State Key Laboratory of Biotherapy, West China Hospital, West China Medical School, Sichuan University, \\ Chengdu, Sichuan 610041, P. R. China
}

§ Department of Chemistry, University of Virginia, Charlottesville, VA 22904-4319, USA

\section{Abstract}

The tetrahydroxyl derivative of BINOL, $(S)$ - or $(R)-\mathbf{1}$, and its analogs are synthesized. (S)- or $(R)-\mathbf{1}$ can be used to conduct the enantioselective recognition of chiral amino alcohols. In comparison with BINOL, the two additional hydroxyl groups of $(S)$ - or $(R)-\mathbf{1}$ have increased the binding of this compound with the amino alcohols and significantly improved the fluorescence quenching efficiency. The fluorescence responses of $(S)$ - or $(R)-\mathbf{1}$ towards amino alcohols are compared with those of its analogs $(R)-\mathbf{4}$ and $(R)-\mathbf{6}$. It shows that the interaction of the central naphthyl hydroxyl groups of $(S)$ - or $(R)-\mathbf{1}$ with the substrates is responsible for the observed fluorescence quenching and the two additional alkyl hydroxyl groups increase the quenching efficiency.

\section{Introduction}

1,1'-Bi-2-naphthol (BINOL) and its derivatives have been extensively used in chiral recognition and asymmetric catalysis. ${ }^{1}$ Because of the fluorescence properties of the<smiles>O=[N+]([O-])c1ccc(O)c(-c2c(O)ccc3ccccc23)c1</smiles>

naphthalene groups in these compounds, their fluorescence responses toward various chiral molecules have also been investigated. 2,3 For example, in 1992, Iwanek and Mattay reported that the fluorescence of BINOL could be quenched by chiral amines with a small degree of enantioselectivity for certain substrates. ${ }^{2 \mathrm{~d}}$ In recent years, there is growing interest in 
developing enantioselective fluorescent sensors for organic compounds since these sensors can potentially provide a real time analytical tool for rapid chiral assay. ${ }^{2-4}$ In order to improve the fluorescent recognition of BINOL for amino alcohols and amines, we have attempted to increase the intermolecular hydrogen binding capability of BINOL by introducing additional hydroxyl groups adjacent to the central diols. For this purpose, compound $(R)-\mathbf{1}$ and its derivatives have been studied and a significantly improved efficiency in the fluorescent recognition of chiral amino alcohols has been observed. Herein, these results are reported.

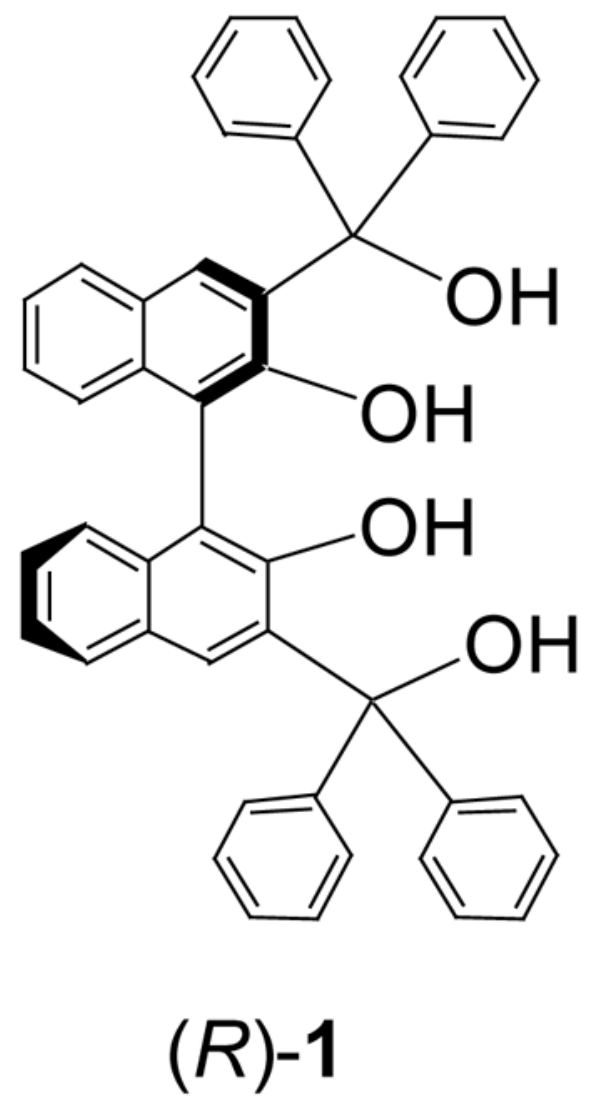

\section{Results and Discussion}

\section{Synthesis and ${ }^{1} \mathrm{H}$ NMR Analyses of $(R)-1,(R)-4$ and $(R)-6$}

The synthesis of the tetrahydroxyl 1,1'-binaphthyl compound $(R)-\mathbf{1}$ was previously reported by Chen ${ }^{5 \mathrm{a}}$ and Kozlowski $5 \mathrm{~b}$ but only low yield and low enantiomeric purity were observed from the asymmetric biaryl coupling reactions. We conducted the ortho-metallation of the enantiomerically pure $(R)-2$ with ${ }^{\mathrm{n}} \mathrm{BuLi}$ (Scheme 1$) .6$ Addition of benzophenone led to the formation of $(R)-3$ in $95 \%$ yield which upon hydrolysis under acidic condition gave the optically pure tetraol $(R)-\mathbf{1}$ in $90 \%$ yield. A similar method to prepare $(S)$-1 was reported while this work was in progress. ${ }^{7}$

In order to understand the functions of the two types of hydroxyl groups in $(R)-\mathbf{1}$, that is, the two aryl hydroxyls and the two alkyl hydroxyls, we synthesized compounds $(R)-\mathbf{4}$ and $(R)-6$ where the hydroxyls are selectively protected with methyl groups (Scheme 2 and 3 ). Reaction of $(R)-\mathbf{1}$ with methanol in the presence of trifluoroacetic acid gave $(R)-\mathbf{4}$ in $82 \%$ yield (Scheme $2)$. In $(R)-\mathbf{4}$, its alkyl hydroxyls were protected. The ortho-metallation of $(R)-2,2^{\prime}-$ dimethoxy-1,1'-binaphthalenyl, ${ }^{8}(R)-\mathbf{5}$, with ${ }^{\mathrm{n}} \mathrm{BuLi}$ in the presence of TMEDA followed by 
addition of benzophenone gave (R)-6 in $60 \%$ yield (Scheme 3 ). In this compound, the two aryl hydroxyls are protected.

The ${ }^{1} \mathrm{H}$ NMR spectrum of $(R)-\mathbf{1}$ in $\mathrm{CDCl}_{3}$ was compared with those of $(R)-\mathbf{4}$ and $(R)-\mathbf{6}$. It was found that the hydroxyl protons of $(R)-\mathbf{4}$ showed the most down-field chemical shift at $\delta 8.49$ $(\mathrm{s}, 2 \mathrm{H}) .(R)-1$ gave two hydroxyl proton signals at $\delta 6.53(\mathrm{~s}, 2 \mathrm{H})$ and $4.64(\mathrm{~s}, 2 \mathrm{H})$, and $(R)-6$ gave one hydroxyl signal at $\delta 5.56(\mathrm{~s}, 2 \mathrm{H})$. The strong intramolecular hydrogen bonds of $(R)-\mathbf{4}$ due to the combination of the more acidic aryl hydroxyl protons with the more basic alkyl methoxyl oxygens probably contributed to its most down field hydroxyl proton signal. The less acidic alkyl hydroxyl protons of $(R)-6$ might not form a strong hydrogen bond with the less basic aryl methoxyl oxygens and a much smaller chemical shift was observed for its hydroxyl protons. $(R)-\mathbf{1}$ contained two types of protons, and the more acidic aryl hydroxyl protons might form intramolecular hydrogen bonds but the less acidic alkyl hydroxyl protons might not.

\section{Optical Spectroscopic Studies of $(R)-1,(R)-4$ and $(R)-6$}

The UV spectra of $(R)-\mathbf{1},(R)-\mathbf{4},(R)-\mathbf{6}$ and $(R)$-BINOL are compared. The longest absorption band of $(R)-4$ is significantly red-shifted $\left(\lambda_{\max }=342 \mathrm{~nm}\right)$ relative to those of the other compounds. This could be attributed to the more polarized O-H bonds of $(R)-\mathbf{4}$ due to the strong intramolecular interaction between its acidic aryl hydroxyl protons and the basic alkyl methoxyl oxygens. The longest wavelength absorption band of $(R)-6$ is blue-shifted $\left(\lambda_{\max }=\right.$ $327 \mathrm{~nm}$ ) because of the methyl protection of the aryl hydroxyl groups. $(R)-\mathbf{1}$ and BINOL have similar UV absorptions at the long wavelengths. At the short wavelengths, $(R)-\mathbf{1}$ shows increased intensity with a slightly red-shifted maximum relative to that of BINOL due to the alkyl substituents at the $3,3^{\prime}$-positions.

The fluorescence spectra of compounds $(R)-\mathbf{1},(R)-\mathbf{4},(R)-\mathbf{6}$ and $(R)$-BINOL in methylene chloride were obtained. As shown in Figure 1, the emission maximums of $(R)-\mathbf{1}$ and $(R)-\mathbf{4}$, both at $379 \mathrm{~nm}$, are similar to that of $(R)-\mathrm{BINOL}$, at $372 \mathrm{~nm}$, with small red-shifts. However, $(R)-6$ exhibits a greatly increased emission signal at $\lambda_{\mathrm{em}}=361 \mathrm{~nm}$ with over $10 \mathrm{~nm}$ blue shifts from those of $(R)-\mathbf{1},(R)-\mathbf{4}$ and $(R)$-BINOL. This indicates that the acidic aryl hydroxyl groups of $(R)-\mathbf{1},(R)-\mathbf{4}$ and $(R)$-BINOL significantly quenched their fluorescence probably due to intraor intermolecular hydrogen bonds and/or proton transfer at the excited states.

We also found that addition of hexane to the methylene chloride solution of $(R)-\mathbf{1}$ caused only a small change in its fluorescence. Later, hexane will be added to the methylene chloride solution of this compound to encourage its hydrogen bonding interaction with chiral amino alcohols.

\section{Enantioselective Fluorescent Recognition of Chiral Amino Alcohols and a Chiral Diamine Using $(R)-1$ and Its Analogs. ${ }^{9}$}

As shown in the above section, introduction of two additional hydroxyl groups in $(R)-\mathbf{1}$ does not significantly change its UV absorption and fluorescence spectroscopic properties from those of $(R)$-BINOL. We compared their fluorescence responses in the presence of an amino alcohol. Figure 2 gives the fluorescence spectra of $(R)-\mathbf{1}$ and $(R)$-BINOL before and after they were treated with $(R)$-phenylalaninol, $(R)$-7. It shows that the amino alcohol quenched the fluorescence of $(R)-\mathbf{1}\left(\mathrm{I}_{0} / \mathrm{I}=4.0\right)$ much more efficiently than that of $(R)$-BINOL $\left(\mathrm{I}_{0} / \mathrm{I}=1.4\right)$. 


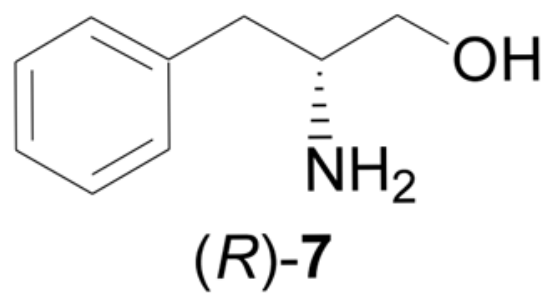

We further studied the fluorescence responses of $(R)-\mathbf{1}$ in the presence of both enantiomers of 7. It was found that the fluorescence of $(R)-1$ at $1.0 \times 10^{-5} \mathrm{M}$ was quenched by the optically pure $(R)$ - and $(S)-7$ with significantly different efficiency. In the concentration range studied, the fluorescence quenching follows the Stern-Völmer equation: ${ }^{10}$

$$
I_{0} / I=1+K_{\mathrm{SV}}[\mathrm{Q}]
$$

where $I_{0}$ is the fluorescence intensity in the absence of a quencher and $I$ the fluorescence intensity in the presence of a quencher. [Q] is the quencher concentration. $K_{\mathrm{SV}}$ is the SternVölmer constant, which measures the efficiency of quenching. Figure 3 shows the SternVölmer plot of $(R)-\mathbf{1}\left(1.0 \times 10^{-5} \mathrm{M}\right)$ in the presence of $(R)$ - and $(S)-7\left(2.0 \times 10^{-3}-6.0 \times\right.$ $10^{-3} \mathrm{M}$ ) in a mixed solvent of methylene chloride and hexane (30:70). The error bars in the plot are in the range of $-13 \%-+15 \%$. The Stern-Völmer constant of $(R)-\mathbf{1}$ is $389 \mathrm{M}^{-1}$ $\left(K_{\mathrm{SV}}{ }^{\mathrm{R}, \mathrm{R}}\right)$ in the presence of $(R)-7$ and $309 \mathrm{M}^{-1}\left(K_{\mathrm{SV}}{ }^{\mathrm{R}, \mathrm{S}}\right)$ in the presence of $(S)-7$. Thus, $(R)-\mathbf{7}$ quenches the fluorescence of $(R)-\mathbf{1}$ more efficiently than $(S)-\mathbf{7}$ with $\mathrm{K}_{\mathrm{SV}}{ }^{\mathrm{RR}} / \mathrm{K}_{\mathrm{SV}}{ }^{\mathrm{RS}}=$ 1.26 .

We also prepared $(S)$-1, the enantiomer of $(R)-\mathbf{1}$, and studied its interaction with $(R)$ - and $(S)-7$ which showed the opposite enantioselectivity. That is, $(S)-\mathbf{7}$ quenched the fluorescence of $(S)$-1 more efficiently than $(R)-7$. This confirms that the observed differences in the fluorescence quenching are due to chiral discrimination.

The Stern-Völmer constants of $(R)$-BINOL in the presence of $(R)$ - and $(S)-7$ were found to be $106 \mathrm{M}^{-1}$ and $91 \mathrm{M}^{-1}$ respectively under the same conditions as the use of $(R)-\mathbf{1}$. The ratio $K_{\mathrm{SV}}{ }^{\mathrm{R}, \mathrm{R}} / K_{\mathrm{SV}} \mathrm{R}^{\mathrm{R}, \mathrm{S}}$ is 1.16 . Similar to $(R)-\mathbf{1}$, the $R$ enantiomer of the amino alcohol quenched the fluorescence of $(R)$-BINOL more efficiently than the $S$ enantiomer does.

The amine-induced fluorescence quenching of $(R)$ - and $(S)$-BINOL was attributed to both ground-state hydrogen bonding as well as excited-state deprotonation of individual binaphthol molecules. ${ }^{2 \mathrm{~d}}$ We expect that the fluorescence quenching of $(R)$ - and $(S)$-1 by the amino alcohol should involve similar mechanisms. Thus, the additional hydroxyl groups of $(R)-\mathbf{1}$ might have increased the interaction of this compound with the amino alcohol both at the ground state and the excited state, leading to the much increased fluorescence quenching. As the concentration of the amino alcohol increased, a new emission signal also appeared at above $500 \mathrm{~nm}$ probably contributed by the deprotonated $(R)$ - or $(S)-\mathbf{1}$ at the excited state.

We also studied the fluorescence of $(S)$-1 in the presence of both enantiomers of chiral phenylglycinol (8), leucinol (9) and valinol (10). All these molecules were found to quench the fluorescence of $(S)$-1 efficiently with certain enantioselectivity. The Stern-Völmer constants, the errors and enantioselective factors of $(S)-\mathbf{1}$ in the presence of the chiral amino alcohols $\mathbf{7 - 1 0}$ are summarized in Table 1 . In all cases, the $(S)$-amino alcohols quenched the fluorescence of $(S)$-1 more efficiently than the $(R)$-amino alcohols did. This indicates that the interaction of $(S)$-1 with the $(S)$-amino alcohols is better than it with the $(R)$-amino alcohols. 

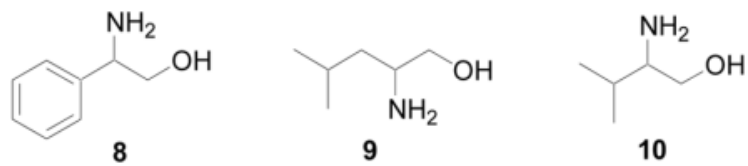

10

The fluorescence responses of $(R)-\mathbf{4}$ and $(R)-\mathbf{6}$ in the presence of the amino alcohols were investigated. As shown in Figure 1, the fluorescence intensity of $(R)-6$ is much greater than that of $(R)-\mathbf{1}$. When $(R)-\mathbf{6}$ was treated with 7, no fluorescence quenching was observed. This demonstrates that the interaction of the central hydroxyl protons with the amino alcohol is essential for the fluorescence quenching of $(R)-\mathbf{1}$. When $(R)-\mathbf{4}$ was interacted with the amino alcohols $\mathbf{7}$ and $\mathbf{9}$, nonmonotonic fluorescence enhancements were observed. It is not clear why the amino alcohols cause the fluorescence enhancement of $(R)-\mathbf{4}$, but the strong intramolecular hydrogen bonds in $(R)-\mathbf{4}$ as indicated by its ${ }^{1} \mathrm{H}$ NMR spectrum should have contributed to this. For example, the intramolecular hydrogen bonds of $(R)-\mathbf{4}$ plus its intermolecular hydrogen bonds with the amino alcohols could lead to the formation of a structurally more rigid complex that could have enhanced fluorescence. This process would be in competition with the amineinduced fluorescence quenching at the central BINOL unit.

However, when $(S)$-1 and $(R)-\mathbf{4}$ were treated with the chiral diamine $(R, R)$ - or $(S, S)-\mathbf{1 1}$, efficient fluorescence quenching was observed for both fluorophores. Thus, the two basic amine groups of $(R, R)$ - or $(S, S)$-11 might have overcome the effect of the intramolecular hydrogen bonds in $(R)-\mathbf{4}$, leading to the expected fluorescence quenching. Figure 4 is the Stern-Völmer plots of $(S)-\mathbf{1}$ in the presence of $(R, R)$ - and $(S, S)-\mathbf{1 1}$ in $\mathrm{CH}_{2} \mathrm{Cl}_{2}$. The Stern-Völmer constants of $(S)-\mathbf{1}$ in the presence of $(R, R)$ - and $(S, S)$-11 are $1175 \mathrm{M}^{-1}$ and $795 \mathrm{M}^{-1}$ respectively, and those of $(R)-\mathbf{4}$ are $807 \mathrm{M}^{-1}$ and $553 \mathrm{M}^{-1}$ respectively. Both $(S)-\mathbf{1}$ and $(R)-\mathbf{4}$ are very sensitive and enantioselective in the fluorescent recognition of the chiral diamine. The fluorescence quenching of $(S)-\mathbf{1}$ by the chirality matched $(R, R)-\mathbf{1 1}$ is more efficient than that of $(R)-\mathbf{4}$ by the chirality-matched $(S, S)$-11. Therefore, the four hydroxyl groups of $(S)$-1 should have provided better binding with the diamine than the two hydroxyl groups of $(R)-\mathbf{4}$. The Stern-Völmer constants of $(R)-1$ in the presence of the diamine are also much greater than those in the presence of the amino alcohols $\mathbf{7 - 1 0}$. This demonstrates that there is a much stronger interaction for $(R)-\mathbf{1}$ with the diamine than with the amino alcohols.
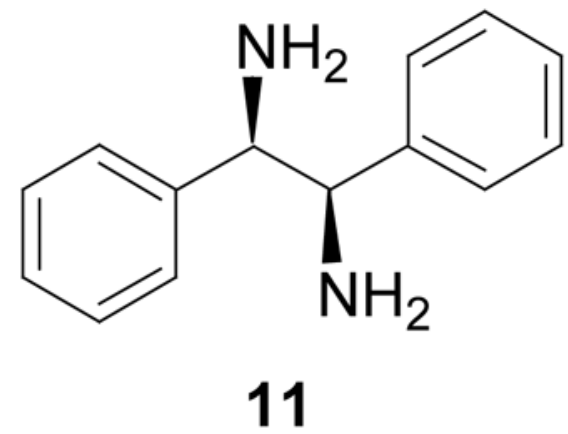

In summary, we have demonstrated that with the introduction of two additional hydroxyl groups to BINOL, the resulting compounds $(S)$ - or $(R)-\mathbf{1}$ have exhibited a significantly improved fluorescent sensitivity towards amino alcohols. Through a selective methylation of the two different types of the hydroxyl groups of $(S)$ - or $(R)-\mathbf{1}$, the roles of these hydroxyl groups in the enantioselective fluorescent recognition of amino alcohols have been identified. The interaction of the central naphthyl hydroxyl groups of $(S)$ - or $(R)-\mathbf{1}$ with the substrates is responsible for the observed fluorescence quenching and the two alkyl hydroxyl groups of $(S)$ - or $(R)-\mathbf{1}$ increase the efficiency of the fluorescence quenching. 


\section{Experimental Section}

\section{Preparation and Characterization of $(R)-3,3^{\prime}-B i s(d i p h e n y l h y d r o x y m e t h y l)-2,2 '-d i-h y d r o x y$ [1,1']binaphthalenyl, $(R)-1$}

(a) Preparation of $(\boldsymbol{R})$-3.- Under nitrogen, $(R)-2(5.0 \mathrm{mmol}, 1.87 \mathrm{~g})$ was dissolved in THF $(100 \mathrm{~mL}$, dried with sodium/benzophenone) in a flask equipped with a side arm and a magnetic stirring bar. The solution was cooled to $0{ }^{\circ} \mathrm{C}$ and ${ }^{\mathrm{n}} \mathrm{BuLi}(25.0 \mathrm{mmol}, 2.5 \mathrm{M}$ in hexane, $10 \mathrm{~mL})$ was added dropwise. The reaction mixture was stirred for $3 \mathrm{~h}$ at $0{ }^{\circ} \mathrm{C}$ and benzophenone $(15.0$ $\mathrm{mmol}, 2.73 \mathrm{~g}$ ) was added as a solid. The reaction was allowed to warm to room temperature overnight and quenched with saturated aqueous $\mathrm{NH}_{4} \mathrm{Cl}$ solution. THF was removed in vacuo and the aqueous solution was extracted with $\mathrm{CH}_{2} \mathrm{Cl}_{2}$. The organic phase was dried with $\mathrm{MgSO}_{4}$ and evaporated to dryness. The residue was recrystallized from benzene and methanol to afford $(R)-\mathbf{3}$ as a white solid in $95 \%$ yield $(3.51 \mathrm{~g})$. $(S)$-3 was prepared from $(S)-\mathbf{2}$ with the same procedure. ${ }^{1} \mathrm{H}$ NMR $\left(400 \mathrm{MHz}, \mathrm{CDCl}_{3}\right) \delta 7.63(\mathrm{~d}, \mathrm{~J}=8.0 \mathrm{~Hz}, 2 \mathrm{H}), 7.44(\mathrm{~d}, \mathrm{~J}=8.8 \mathrm{~Hz}$, $4 \mathrm{H}), 7.37-7.26(\mathrm{~m}, 20 \mathrm{H}), 7.19(\mathrm{~d}, \mathrm{~J}=8.4 \mathrm{~Hz}, 2 \mathrm{H}), 7.15(\mathrm{~s}, 2 \mathrm{H}), 5.80(\mathrm{~s}, 2 \mathrm{H}), 3.81(\mathrm{~d}, \mathrm{~J}=4.8$ $\mathrm{Hz}, 2 \mathrm{H}), 3.77(\mathrm{~d}, \mathrm{~J}=4.8,4 \mathrm{H}), 2.82(\mathrm{~s}, 6 \mathrm{H})$. ESI-MS m/z: $761.4\left(\mathrm{M}+\mathrm{Na}^{+}, 100\right)$.

(b) Preparation of $(\boldsymbol{R})$-1-Under nitrogen, $(R)-\mathbf{3}(10.9 \mathrm{mmol}, 8.08 \mathrm{~g})$ was dissolved in THF $(160 \mathrm{~mL})$ to which $3 \mathrm{~N} \mathrm{HCl}(30 \mathrm{~mL})$ was added. After the mixture was heated at reflux $\left(80^{\circ}\right.$ C) for $6 \mathrm{~h}, 10 \% \mathrm{NaHCO}_{3}(100 \mathrm{~mL})$ was added to quench the reaction. The mixture was extracted with ethyl acetate and the organic phase was washed with water and dried with $\mathrm{MgSO}_{4}$. After evaporation, the residue was dissolved in diethyl ether, and precipitated with petroleum ether. The precipitate was recrystallized from acetone to afford $(R)-\mathbf{1}$ as a white solid in $90 \%$ yield $(6.40 \mathrm{~g})$. $(S)$-1 was also prepared from $(S)-\mathbf{3}$ with the same procedure. The optical purity of $(R)-1$ was $95 \%$ ee as determined by using HPLC-Chiralcel OD column (Solvent: Hexane/ $/ \mathrm{PrOH}=20 / 80$, Flow rate: $0.3 \mathrm{~mL} / \mathrm{min})$. The specific optical rotation of $(R)-\mathbf{1}$, $[\alpha]_{\mathrm{D}}^{20}$, is $+113.4\left(\mathrm{c}=1.00, \mathrm{CHCl}_{3}\right)$, and that of $(S)-\mathbf{1},[\alpha]_{\mathrm{D}}{ }^{20}$, is $-109.5\left(\mathrm{c}=1.00, \mathrm{CHCl}_{3}\right) .{ }^{1} \mathrm{H}$ NMR (400 MHz, CDCl $)_{3} \delta 7.60$ (d, J = 9.2 Hz, 2H), 7.35-7.22 (m, 24H), 7.13 (s, 2H), 7.09 (d, $\mathrm{J}=8.8 \mathrm{~Hz}, 2 \mathrm{H}), 6.57(\mathrm{~s}, 2 \mathrm{H}), 4.65(\mathrm{~s}, 2 \mathrm{H}) .{ }^{13} \mathrm{C}$ NMR $\left(50 \mathrm{MHz}, \mathrm{CDCl}_{3}\right) \delta 151.3,145.4,145.2$, 133.9, 133.4, 131.0, 129.0, 128.2, 128.1, 128.0, 127.6, 127.3, 124.2, 124.1, 114.4, 83.0. ESIMS: $\mathrm{m} / \mathrm{z} 649.3\left(\mathrm{M}-\mathrm{H}^{+}, 100\right)$. HRMS calcd for $\mathrm{C}_{46} \mathrm{H}_{34} \mathrm{Na}_{1} \mathrm{O}_{4}(\mathrm{M}+\mathrm{Na}): 673.2349$. Found: 673.2338. Anal. Calcd for $\mathrm{C}_{46} \mathrm{H}_{36} \mathrm{O}_{5}\left((R)-1+\mathrm{H}_{2} \mathrm{O}\right): \mathrm{C}, 82.61 ; \mathrm{H}, 5.43$. Found: $\mathrm{C}, 82.50 ; \mathrm{H}$, 5.62 .

\section{Preparation and Characterization of $(R)-3,3^{\prime}-B i s(d i p h e n y l m e t h y l m e t h o x y l)-2,2 '-d i h y d r o x y$ [1,1']binaphthalenyl, $(R)-4$}

Under nitrogen, $(R)-\mathbf{1}(2.4 \mathrm{mmol}, 1.52 \mathrm{~g})$ was dissolved in $\mathrm{CH}_{2} \mathrm{Cl}_{2}(35 \mathrm{~mL})$ and $\mathrm{CH}_{3} \mathrm{OH}(120$ $\mathrm{mL}) . \mathrm{CF}_{3} \mathrm{CO}_{2} \mathrm{H}(1 \mathrm{~mL})$ was added at $0^{\circ} \mathrm{C}$. The mixture was gradually warmed up to room temperature. The reaction progress was monitored by conducting thin layer chromatography on silica gel. In about $8 \mathrm{~h}$, there was a white precipitate in the mixture. $\mathrm{CH}_{2} \mathrm{Cl}_{2}(35 \mathrm{~mL})$ was added to dissolve the precipitate, and the mixture was neutralized to $\mathrm{pH} 6-7$ with $3 \%$ $\mathrm{NaHCO}_{3}$. It was extracted with $\mathrm{CH}_{2} \mathrm{Cl}_{2}$ and the organic phase was washed with water and dried with $\mathrm{MgSO}_{4}$. After removal of the volatile solvent under reduced pressure, the residue was passed through a silica gel column eluted with EtOAc/petroleum ether (1/9) to afford $(R)-\mathbf{4}$ as a light yellow solid in $82 \%$ yield $(1.31 \mathrm{~g}) .{ }^{1} \mathrm{H}$ NMR $\left(400 \mathrm{MHz}, \mathrm{CDCl}_{3}\right) \delta 8.51(\mathrm{~s}, 2 \mathrm{H})$, $7.65(\mathrm{~d}, \mathrm{~J}=9.2 \mathrm{~Hz}, 4 \mathrm{H}), 7.51-7.45(\mathrm{~m}, 8 \mathrm{H}), 7.40-7.10(\mathrm{~m}, 16 \mathrm{H}), 6.97(\mathrm{~d}, \mathrm{~J}=8.0 \mathrm{~Hz}, 2 \mathrm{H}), 3.30$ (s, 6H). ${ }^{13} \mathrm{C}$ NMR $\left(50 \mathrm{MHz}, \mathrm{CDCl}_{3}\right) \delta 152.0,141.7,140.8,133.8,130.3,130.2,129.6,128.5$, 128.1, 127.9, 127.8, 127.6, 126.7, 124.5, 123.2, 117.6, 90.3, 53.1. $[\alpha]_{\mathrm{D}}{ }^{20}=+192.1(\mathrm{c}=1.01$, $\mathrm{CHCl}_{3}$ ). HRMS calcd for $\mathrm{C}_{48} \mathrm{H}_{38} \mathrm{Na}_{1} \mathrm{O}_{4}(\mathrm{M}+\mathrm{Na}): 701.2662$. Found: 701.2654. Anal. Calcd for $\mathrm{C}_{48} \mathrm{H}_{38} \mathrm{O}_{4}$ : C, 84.93; H, 5.64. Found: $\mathrm{C}, 84.72 ; \mathrm{H}, 5.58$. 


\section{Preparation and Characterization of (R)-3,3'-Bis(diphenylhydroxymethyl)-2,2'-dimethoxy [1,1']binaphthalenyl, $(R)-6$}

Under nitrogen, diethyl ether $(100 \mathrm{~mL}$, dried) and TMEDA $(15.0 \mathrm{mmol}, 1.75 \mathrm{~g})$ were placed in a $250 \mathrm{~mL}$ three-necked round-bottomed flask equipped with a side arm and a magnetic stirring bar. To this solution was added ${ }^{\mathrm{n}} \mathrm{BuLi}(20.0 \mathrm{mmol}, 2.5 \mathrm{M}$ in hexane, $8 \mathrm{~mL})$ dropwise. It was then stirred at room temperature for $30 \mathrm{~min} .(R)-2,2^{\prime}$-Dimethoxy-1,1'-binaphthalenyl, $(R)-5$ (5.0 mmol, $1.55 \mathrm{~g})$, was added in one portion, and the reaction mixture was stirred for 3 h. Benzophenone $(15.0 \mathrm{mmol}, 2.73 \mathrm{~g})$ in diethyl ether $(10 \mathrm{~mL})$ was added to the resulting light brown suspension via syringe over $10 \mathrm{~min}$. The reaction mixture was stirred overnight and quenched with saturated aqueous $\mathrm{NH}_{4} \mathrm{Cl}$ solution. The volatile solvent was removed in vacuum and the remaining aqueous solution was extracted with $\mathrm{CH}_{2} \mathrm{Cl}_{2}$. The organic phase was dried over $\mathrm{MgSO}_{4}$ and evaporated to dryness. The residue was passed through a silica gel column eluted with $\mathrm{CH}_{2} \mathrm{Cl}_{2} /$ petroleum ether/EtOAc (1/1/0.001) to afford $(R)-6(2.01 \mathrm{~g})$ as a white solid in $60 \%$ yield. ${ }^{1} \mathrm{H}$ NMR $\left(400 \mathrm{MHz}, \mathrm{CDCl}_{3}\right) \delta 7.63(\mathrm{~d}, \mathrm{~J}=8.0 \mathrm{~Hz}, 2 \mathrm{H}), 7.44-7.20(\mathrm{~m}, 26 \mathrm{H}), 7.14$ $(\mathrm{s}, 2 \mathrm{H}), 5.56(\mathrm{~s}, 2 \mathrm{H}), 2.41(\mathrm{~s}, 6 \mathrm{H}) .{ }^{13} \mathrm{C}$ NMR $\left(50 \mathrm{MHz}, \mathrm{CDCl}_{3}\right) \delta 155.6,147.4,145.5,140.7$, 133.8, 130.0, 129.3, 128.7, 128.5, 128.3, 127.9, 127.8, 127.5, 127.3, 127.1, 126.9, 126.5, 125.2, 125.1, 124.1, 82.2, 60.1. $[\alpha]_{\mathrm{D}}{ }^{20}=+84.2\left(\mathrm{c}=5.02, \mathrm{CHCl}_{3}\right)$. HRMS calcd for $\mathrm{C}_{48} \mathrm{H}_{38} \mathrm{Na}_{1} \mathrm{O}_{4}(\mathrm{M}$ $+\mathrm{Na}):$ 701.2662. Found 701.2675. Anal. Calcd for $\mathrm{C}_{48} \mathrm{H}_{40} \mathrm{O}_{5}\left((R)-5+\mathrm{H}_{2} \mathrm{O}\right): \mathrm{C}, 82.73 ; \mathrm{H}, 5.79$. Found: C, 82.37; H, 5.60.

\section{Preparation of Samples for Fluorescence Measurement}

All solutions were prepared using volumetric syringes, pipettes and volumetric flasks. The stock solutions of fluorophores and quenchers were freshly prepared and used for each measurement. For the fluorescence quenching study, a fluorophore solution was mixed with the amino alcohol and amine solutions in a $10 \mathrm{~mL}$ volumetric flask and diluted to the desired concentration. The resulting solution was allowed to stand at room temperature for $3-4 \mathrm{~h}$ before the fluorescence measurement in order to allow the interaction to reach equilibrium. For each series of experiments, three independent fluorescence measurements were carried out. The average value of the Stern-Völmer constant was given in all the plots.

\section{Supplementary Material}

Refer to Web version on PubMed Central for supplementary material.

\section{Acknowledgements}

This work was supported by the National Natural Science Foundation of China (No. 20328203, 20272039), Program for New Century Excellent Talents in University and Scientific Fund of Sichuan Province for Outstanding Young scientist. LP thanks the partial support of this work from the US National Institute of Health (R01GM58454/ R01EB002037-05) and Changiiang Scholarship of the Educational Ministry of China.

\section{References}

1. (a) Pu L. Chem Rev 1998;98:2405-2494. [PubMed: 11848968] (b) Kocovsky P, Vyskocil S, Smrcina M. Chem Rev 2003;103:3213-3245. [PubMed: 12914496] (c) Walsh PJ, Lurain AE, Balsells J. Chem Rev 2003;103:3297-3344. [PubMed: 12914499] (d) Brunel JM. Chem Rev 2005;105:857-897. [PubMed: 15755079]

2. (a) Irie M, Yorozu T, Hayashi K. J Am Chem Soc 1978;100:2236-2237. (b) Yorozu T, Hayashi K, Irie M. J Am Chem Soc 1981;103:5480-5484. (c) Avnir D, Wellner E, Ottolenghi M. J Am Chem Soc 1989;111:2001-2003. (d) Iwanek W, Mattay J. J Photochem Photobiol A: Chem 1992;67:209-226. (e) James TD, Sandanayake KRAS, Shinkai S. Nature 1995;374:345-347. (f) James TD, Sandanayake KRAS, Iguchi R, Shinkai S. J Am Chem Soc 1995;117:8982-8987. (g) Parker KS, Townshend A, Bale SJ. Anal Proc 1995;32:329-332. (h) Kubo Y. Synlett 1999;2:161-174. (i) Beer G, Rurack K, Daub J. J Chem Soc, Chem Commun 2001:1138-1139. 
3. A review on the enantioselective fluorescent recognition of chiral organic molecules: (a) Pu L. Chem Rev 2004;104:1687-1716. [PubMed: 15008630] (b) Pugh V, Hu QS, Pu L. Angew Chem, Int Ed 2000;39:3638-3641. (c) Lin J, Hu QS, Xu MH, Pu L. J Am Chem Soc 2002;124:2088-2089. [PubMed: 11878942] (d) Xu MH, Lin J, Hu QS, Pu L. J Am Chem Soc 2002;124:14239-14246. [PubMed: 12440923] (e) Li ZB, Lin J, Pu L. Angew Chem, Int Ed 2005;44:1690-1693.

4. (a) Mei X, Wolf C. J Am Chem Soc 2004;126:14736-14737. [PubMed: 15535695] (b) Reetz MT, Sostmann S. Tetrahedron 2001;57:2515-2520. (c) Xu YF, McCarroll ME. J Phys Chem A 2004;108:6929-6932.

5. (a) Barhate NB, Chen C. Org Lett 2002;4:2529-2532. [PubMed: 12123368] (b) Li XL, Hewgley B, Mulrooney CA, Yang J, Kozlowski MC. J Org Chem 2003;68:5500-5511. [PubMed: 12839440]

6. Cox PJ, Wang W, Snieckus V. Tetrahedron Lett 1992;33:2253-2256.

7. Dixon DI, Tillman AL. Synlett 2005;17:2635-2638.

8. Lingenfelter DS, Helgeson RG, Gram DJ. J Org Chem 1981;46:393-406.

9. Selected recent work on the chiral recognition of amino alcohols: (a) Tsubaki K, Tanima D, Nuruzzaman M, Kusumoto T, Fuji K, Kawabata T. J Org Chem 2005;70:4609-4616. [PubMed: 15932296] (b) Kim KM, Park H, Kim H-J, Chin J, Nam W. Org Lett 2005;7:3525-3527. [PubMed: 16048333] (c) Dai ZH, Xu XD, Canary JW. Chirality 2005;17:S227-S233. [PubMed: 15952135] (d) Lee SL, Lin WB. J Am Chem Soc 2002;124:4554-4555. [PubMed: 11971690] (e) Liu Y, Li B, Wada T, Inoue Y. Tetrahedron 2001;57:7153-7161. (f) Reetz MT, Sostmann S. Tetrahedron 2001;57:25152520.

10. Lakowicz, JR. Principles of Fluorescence Spectroscopy. 1. Plenum Press; New York: 1983. p. 257-301. 


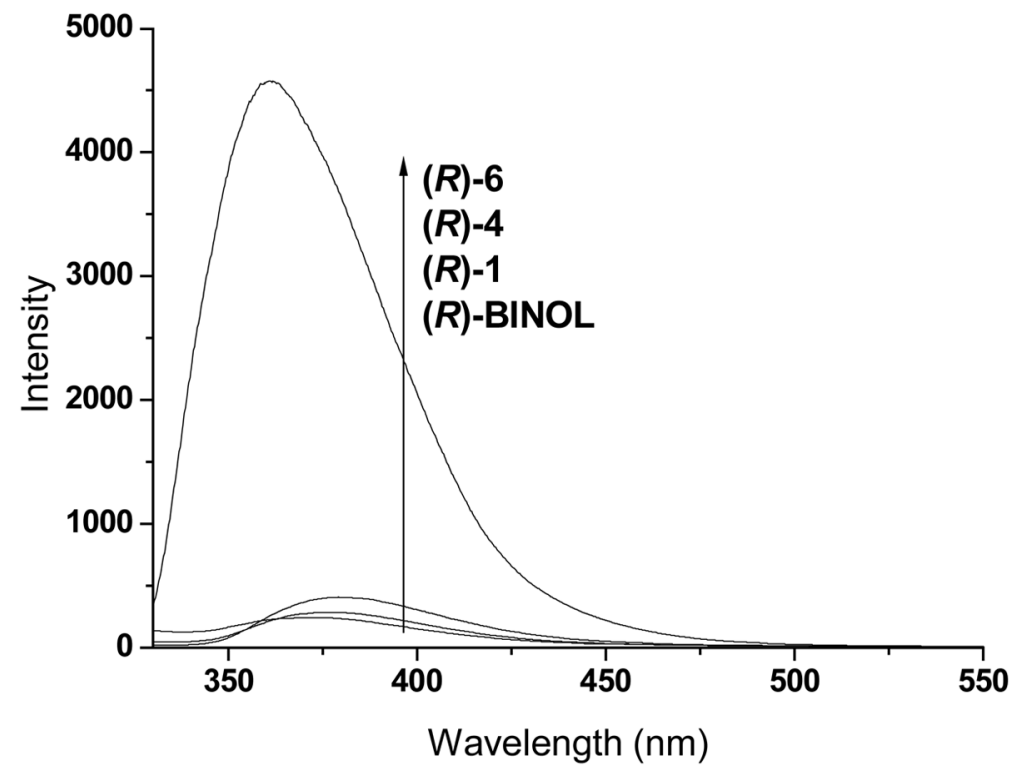

Figure 1.

Fluorescence Spectra of $(R)$-BINOL, $(R)-\mathbf{1},(R)-\mathbf{4}$ and $(R)-\mathbf{6}$ in $\mathrm{CH}_{2} \mathrm{Cl}_{2}\left(8.0 \times 10^{-6} \mathrm{M}, \lambda_{\text {exc }}\right.$ at 294, 298, 298 and $302 \mathrm{~nm}$, respectively, emission slits: $5.0 \mathrm{~nm}$ ). 


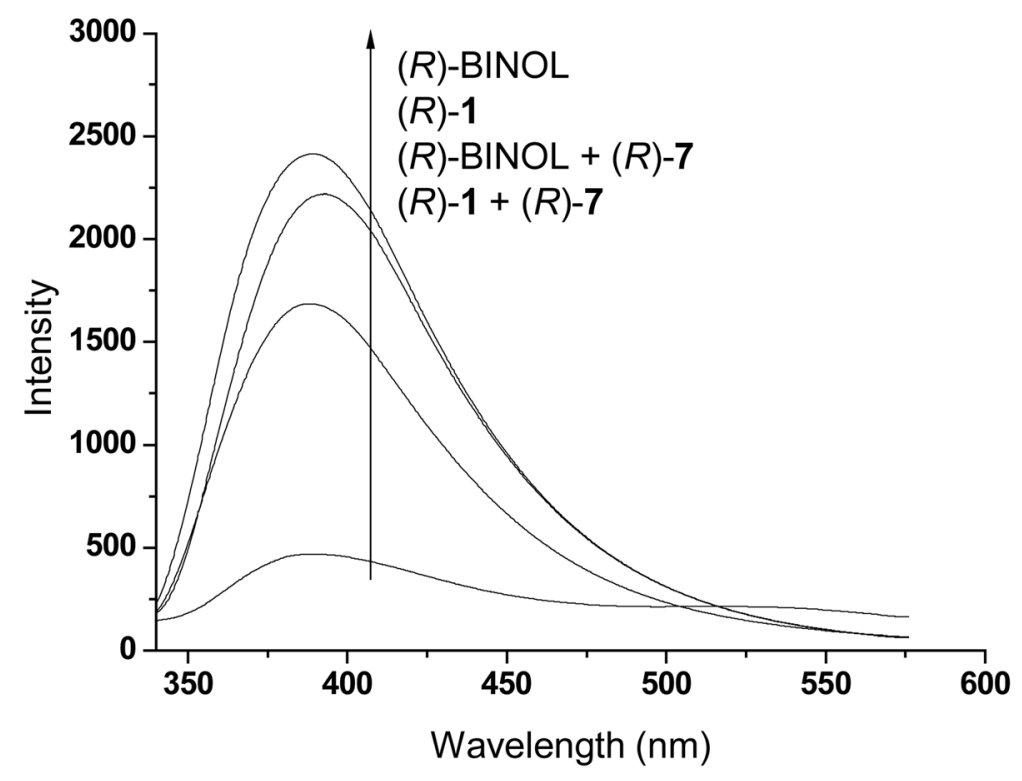

Figure 2.

Fluorescence Spectra of $(R)-\mathbf{1}$ and $(R)$-BINOL (both at $1.0 \times 10^{-5} \mathrm{M}$ ) in $\mathrm{CH}_{2} \mathrm{Cl}_{2} /$ hexane (30:70) with and without $(R)-7\left(8.0 \times 10^{-3} \mathrm{M}\right)\left(\lambda_{\mathrm{exc}}\right.$ at 298 and $300 \mathrm{~nm}$ respectively). 


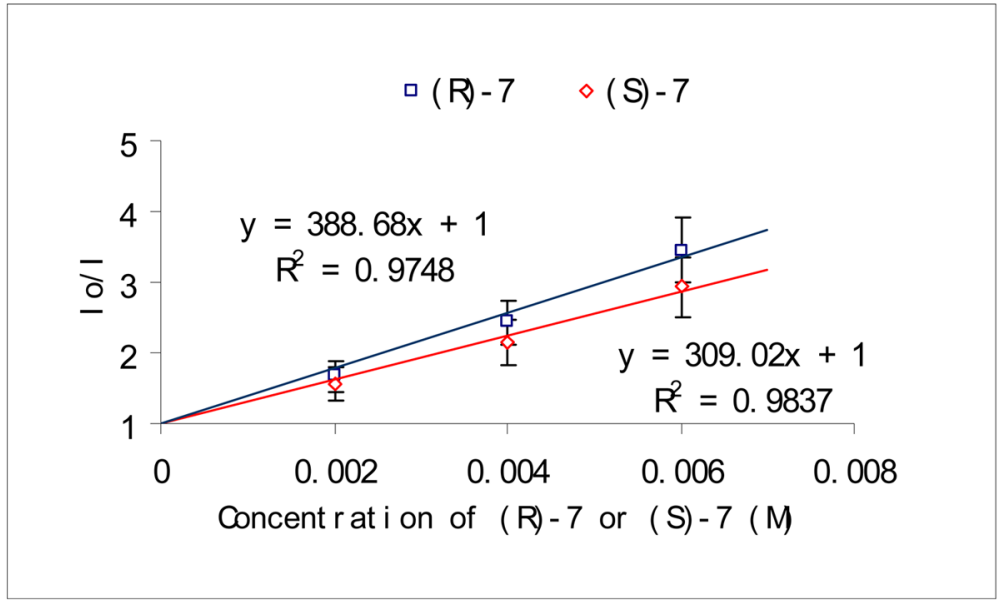

Figure 3.

Stern-Völmer Plot of $(R)-\mathbf{1}\left(1.0 \times 10^{-5} \mathrm{M}\right)$ in $\mathrm{CH}_{2} \mathrm{Cl}_{2} /$ hexane (30:70) in the presence of $(R)$ and $(S)-7\left(\lambda_{\text {exc }}=298 \mathrm{~nm}\right)$. 


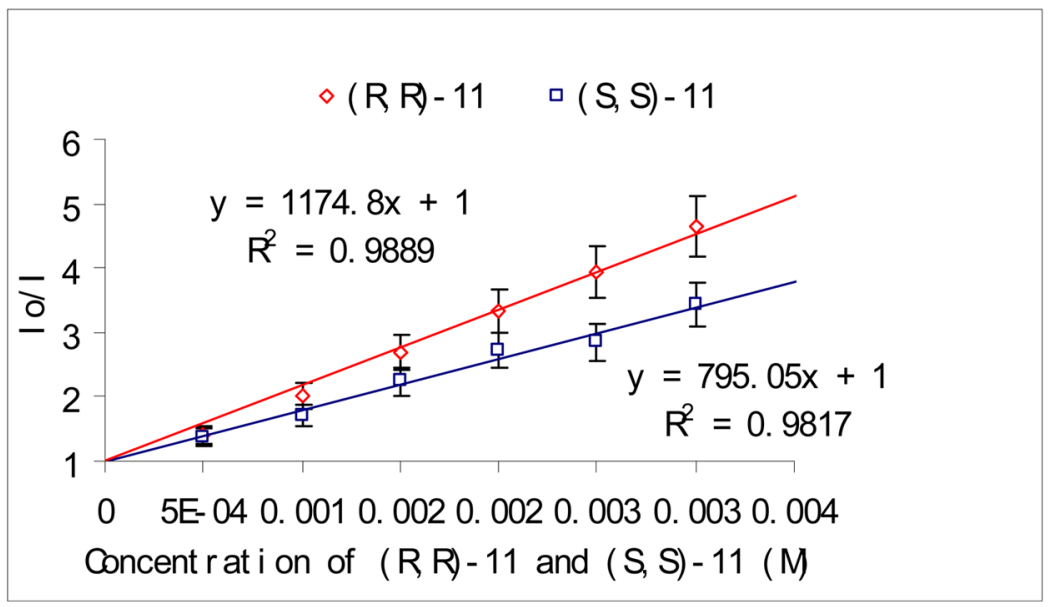

Figure 4.

Stern-Völmer Plot of $(S)-\mathbf{1}\left(1.0 \times 10^{-5} \mathrm{M}\right)$ in $\mathrm{CH}_{2} \mathrm{Cl}_{2}$ in the presence of $(R, R)$ - and $(S, S)-\mathbf{1 1}$ $\left(\lambda_{\text {exc }}=255 \mathrm{~nm}\right)$. 


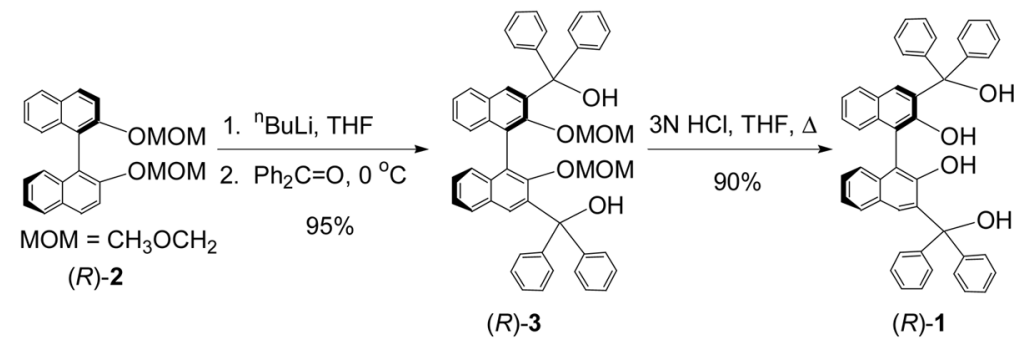

Scheme 1.

Synthesis of the Tetrahydroxyl 1,1'-Binaphthyl (R)-1. 


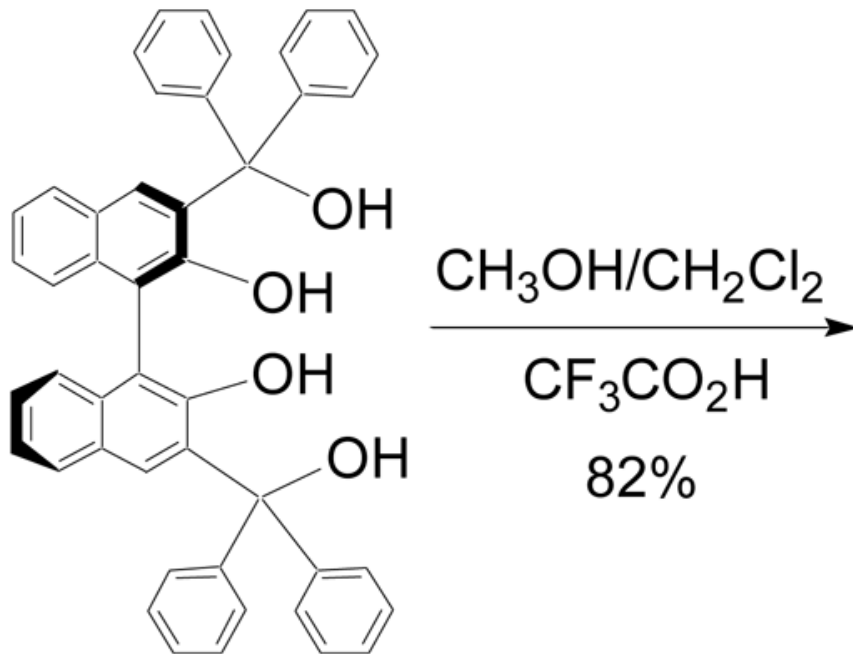

(R)-1

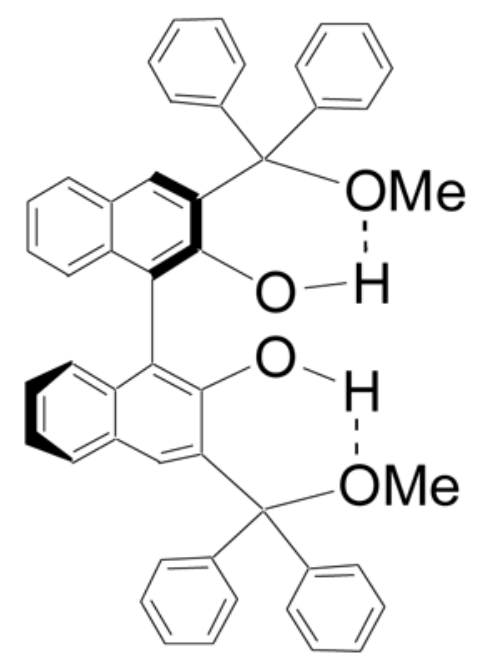

(R)-4

Scheme 2.

Synthesis of $(R)-\mathbf{4}$. 
1. ${ }^{\mathrm{n} B u L i}$, TMEDA 2. $\mathrm{Ph}_{2} \mathrm{C}=\mathrm{O}$

3. $\mathrm{H}_{2} \mathrm{O}$

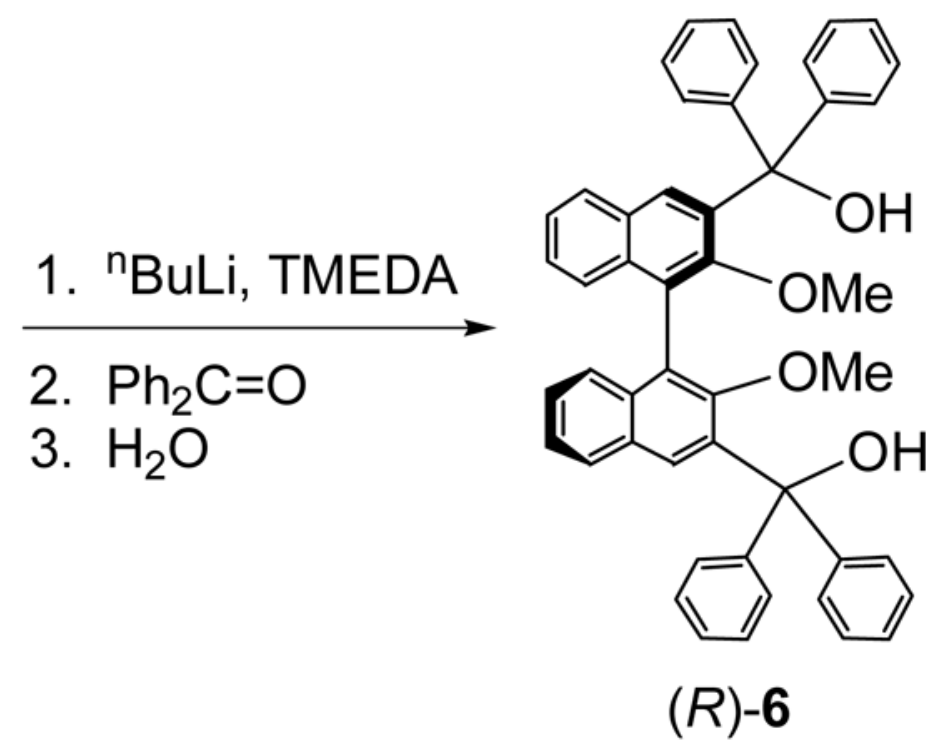

Scheme 3.

Synthesis of $(R)-6$. 


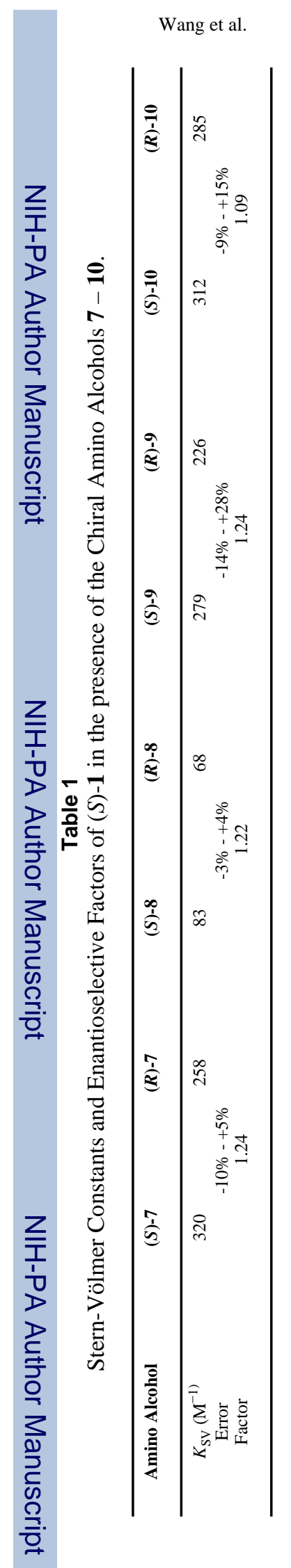

Page 16 